\title{
Locus of the intensity effect in simple reaction time tasks
}

\author{
PIOTR JAŚKOWSKI \\ University of Finance and Management, Warsaw, Poland \\ Marta Kurczewska \\ Adam Mickiewicz University, Poznan, Poland \\ AgnieszKa NowIK \\ Karol Marcinkowski University of Medicine, Poznan, Poland \\ Rob H. J. VAN DER LUBBE \\ University of Twente, Enschede, The Netherlands \\ AND \\ ROLF VERLEGER \\ University of Lübeck, Lübeck, Germany
}

\begin{abstract}
Evidence is still inconclusive regarding the locus of the stimulus intensity effect on information processing in reaction tasks. Miller, Ulrich, and Rinkenauer (1999) addressed this question by assessing the intensity effect on stimulus- and response-locked lateralized readiness potentials (LRPs) as indices of the sensory and motor parts of reaction time (RT). In the case of visual stimuli, they observed that application of brighter stimuli resulted in a shortening of RT and stimulus-locked LRP (S-LRP), but not of response-locked LRP (R-LRP). The results for auditory stimuli, however, were unclear. In spite of a clear RT reduction due to increased loudness, neither S-LRP nor R-LRP onset was affected. A reason for this failure might have been a relatively small range of intensity variation and the type of task. To check for this possibility, we performed three experiments in which broader ranges of stimulus intensities and simple, rather than choice, response tasks were used. Although the intensity effect on the R-LRP was negligible, S-LRP followed RT changes, irrespective of stimulus modality. These findings support the conclusion that stimulus intensity exerts its effect before the start of motoric processes. Finally, S-LRP and R-LRP findings are discussed within a broader information-processing perspective to check the validity of the claim that S-LRP and R-LRP can, indeed, be considered as pure estimates of the duration of sensory and motor processes.
\end{abstract}

Reaction time (RT) is known to decrease as a function of stimulus intensity, approaching an asymptote for the most intense stimuli. This is particularly true for simple reactions, but not always for more complex tasks (see, e.g., van der Molen \& Keuss, 1979). Stimulus intensity has usually been considered a factor influencing only very early stages of information processing. Evidence supporting this view has come both from studies employing the additive factors method (AFM) and from psychophysiological measures. It has been shown that the intensity effect on RT is additive with the effects of other factors, such as foreperiod duration, stimulus-response compatibility, number of alternatives, stimulus probability, and practice (e.g., Everett, Hochhaus, \& Brown, 1985; Miller \& Pachella, 1976; Niemi, 1979; Pachella \& Miller, 1976; Raab, Fehrer, \& Hershenson, 1961; Sanders \& Andriessen, 1978; Schweickert, Dahn, \& McGuigan, 1988; Shwartz, Pomerantz, \& Egeth, 197). Ac- cording to AFM, the additivity of intensity and other factors means that the stage affected by intensity is different from the stages affected by those other factors. Therefore, one might reasonably assume that this particular stage occurs very early in processing, distant from other stages. This claim has gained further support from electrophysiological studies in which the effect of intensity on simple RT and on the latency of early components of event-related potentials (ERPs) have been directly compared. Using this approach, Vaughan, Costa, and Gilden (1966), Wilson and Lit (1981), and Jaśkowski, Pruszewicz, and Swidziński (1990) found that visual intensity had identical effects on simple RT and on the latency of the N1 component. These findings suggested that the processes later than those reflected by the N1 (which peaks at about 100-150 msec) are independent of stimulus intensity. Evidence from a number of other studies, however, is in conflict with this view.

P. Jaśkowski, e-mail: jaskowski@vizja.pl 
For example, Miller and Pachella (1973) showed that stimulus intensity interacted with stimulus probability in a verbal-naming task and in a memory-scanning task with digits as stimuli. Nevertheless, these two factors were later shown to be additive in a same-different matching task (Pachella \& Miller, 1976) and in a memory-scanning task with unfamiliar visual forms as stimuli (Miller \& Pachella, 1976). However, another study by Stanovich and Pachella (1977) additionally revealed an interaction of stimulus-response compatibility and stimulus intensity, the latter finding being difficult to reconcile with the claim that stimulus intensity exerts early effects only. Finally, Jaśkowski, Rybarczyk, and Jaroszyk (1994) found larger effects of stimulus intensity on simple RT than on N1 latency for auditory stimuli, and comparable results were reported for visual stimuli by Kammer, Lehr, and Kirschfeld (1999), which might signify that the locus of stimulus intensity is not restricted to an early processing level.

Thus, both methods - that is, AFM and comparison of RT and ERP latencies - have provided contradictory results. Moreover, being rather debatable, the assumptions of the AFM - that is, serial processing and independence of consecutive processing stages - have been criticized from the very beginning (Külpe, 1895) and are still subject to verification (e.g., Band \& Miller, 1997; Miller \& Low, 2001; Pachella, 1974; Thomas, 2006; Ulrich, Mattes, \& Miller, 1999). Similarly, the direct comparison of effects on RT and latency of early ERP waves has also been questioned. Some authors (Callaway, Halliday, Naylor, \& Thouvenin, 1984; Meyer, Osman, Irwin, \& Yantis, 1988) have argued that these two latency measures are not comparable because of different statistical properties: "The latency of the average is not the average of the latencies," as is stated in the title of Callaway et al.'s contribution (for further discussions, see Smulders, Kenemans, \& Kok, 1994; Verleger, 1997). In defense of such comparisons, it should, however, be emphasized that these findings support the hypothesis that early processes depend on intensity. The open question remains whether the motor part of RT depends on intensity, too. So far, neither AFM nor a comparison of ERP latencies and RT has provided a decisive answer to this question.

Other approaches to this problem additionally failed to give a more definite answer. For example, intensity effects on RT and perceptual latency were compared by using temporal order judgment (TOJ; see Jaśkowski, 1996, for a review) or the Pulfrich stereophenomenon as measures of perceptual latency (see Miller, Ulrich, \& Rinkenauer, 1999, for a review of other approaches). Larger effects of intensity have been reported on simple RT than on TOJ latency both for visual (Jaśkowski, 1992; Jaśkowski \& Verleger, 2000; Roufs, 1974) and for auditory (Sanford, 1971, 1974) stimuli. Comparable results were demonstrated with the Pulfrich effect (Brauner \& Lit, 1976; Williams \& Lit, 1983). The extra effect on simple RT might be assigned to an influence of intensity on postperceptual processes contributing to RT, but not to perceptual latency as measured by both TOJ and the Pulfrich phenomenon. The problem with this interpretation is that the nature of TOJ and the Pulfrich effect is unclear. For example, it is quite obvious that different calculations are needed to determine the order of two stimuli than to trigger a motor response. The different calculations might rely on different time markers of the internal response to a stimulus, which differently depend on stimulus intensity (Jaśkowski, 1996; Sternberg \& Knoll, 1973). The same reasoning applies to the Pulfrich effect (Morgan, 1976, 1977; Morgan \& Thompson, 1975). Thus, again, effects of intensity on the Pulfrich effect and TOJ latency may be used as evidence in favor of the hypothesis that early stages of processing depend on stimulus intensity. However, the dissociations between RT and TOJ/Pulfricheffect latency may not be taken as an argument for an intensity-dependent motor part of RT.

\section{Event-Related Readiness Potentials}

For 2 decades, psychophysiology has been profiting from the use of another ERP index of mental timing, which provides new insights into the duration of RT subprocesses. This is the lateralized readiness potential (LRP; see, e.g., Coles, 1989; for reviews, see Eimer \& Coles, 2003; Leuthold, Sommer, \& Ulrich, 1996; Miller \& Low, 2001; Miller \& Ulrich, 1998; Miller, Ulrich, \& Rinkenauer, 1999; Osman et al., 2000). Prior to the initiation of a voluntary movement, a negative potential can be observed over the human scalp. It is larger over the left than over the right precentral gyrus prior to a right-hand movement, and vice versa for left-hand movements. The moment-by-moment difference between the EEG activity over sensorimotor cortical areas contralateral and ipsilateral to the responding hand is called the LRP.

The onset of the LRP serves as a temporal marker for the moment at which response-specific processes become active (e.g., Coles, 1989). This onset can be determined relative to stimulus presentation (stimulus-locked LRP, or S-LRP) or to the onset of the overt response (responselocked LRP, or R-LRP). If an experimental factor affects processes prior to response initiation, the interval between stimulus onset and the onset of S-LRP should be altered. Conversely, effects on the duration of processes between response initiation and the participant's overt response are most clearly seen in R-LRP. Therefore, R-LRPs and S-LRPs provide us with the possibility to determine whether an experimental manipulation affects the duration of early processes, late processes, or both. This approach has been successfully applied to investigate which of the two subprocesses was affected by stimulus quality (Smulders, Kok, Kenemans, \& Bashore, 1995), the number of alternative responses (Miller \& Ulrich, 1998), speed-accuracy trade-off (Osman et al., 2000; Rinkenauer, Osman, Ulrich, Müller-Gethmann, \& Mattes, 2004; van der Lubbe, Jaśkowski, Wauschkuhn, \& Verleger, 2001), temporal preparation (Müller-Gethmann, Ulrich, \& Rinkenauer, 2003), between-task interference in psychological refractory period (Osman \& Moore, 1993), task complexity (Miller \& Low, 2001; Smulders et al., 1995), exogenous cuing effects (van der Lubbe, Havik, Bekker, \& Postma, 2006), or expectedness of the stimulus (Leuthold, 2003). 


\section{The Effect of Stimulus Intensity on LRP}

Miller, Ulrich, and Rinkenauer (1999) applied LRP measurements to evaluate whether motor processes are affected by stimulus intensity, arguing that this approach is free from the weaknesses of other methods. Miller, Ulrich, and Rinkenauer checked the effect of the intensity of visual (Experiment 1) and auditory (Experiment 2) stimuli on choice RT, R-LRP, and S-LRP. In the case of visual stimuli, the results were quite clear: Application of brighter stimuli resulted in a shortening of RT and an earlier S-LRP but had no effect on the R-LRP. These findings suggest that premotor processes are affected by stimulus intensity, whereas motor processes are not. Unfortunately, the results for auditory stimuli were rather unclear. Although Miller, Ulrich, and Rinkenauer found a significant effect of intensity on RT and N100 and P300 latency, neither S-LRP nor R-LRP onset turned out to be dependent on loudness. The authors tried to explain this null effect by making the assumption that "increasing auditory intensity shortens the latency of early sensory and perceptual processes, prolongs subsequent processes up to the onset of hand-specific response activation, and has no effect on duration of motor processes following hand-specific response activation" (Miller, Ulrich, \& Rinkenauer, 1999, p. 1465). They further speculated about why such two contradictory processes might take place by referring to the effect described by van der Molen and Keuss (Keuss \& van der Molen, 1982; van der Molen \& Keuss, 1979, 1981; van der Molen \& Orlebeke, 1980). Van der Molen and Keuss showed that for auditory stimuli, the relation between RT and loudness depended on the task: Whereas RT monotonically decreased with intensity for the simple and the go/no-go tasks, the relation was flatter or even U-shaped when tasks were more difficult (e.g., the choice or Simon task).

The results of these experiments may be taken to suggest that increasing loudness, although accelerating early processes, slows down more distal processes such as the selection of the response. Thus, Miller, Ulrich, and Rinkenauer (1999) interpreted the lack of intensity effects on S-LRP as due to mutual canceling of the intensity effects on early and late processes during the time interval between onsets of stimulus and S-LRP. Although attractive, this explanation encounters at least one problem: How is it possible that, although neither S-LRP nor R-LRP was affected, nevertheless RT was shortened? In other words, if RT decrease is not due to shortening of motor processes, it has to be reflected in S-LRP, but it is not. Being aware of this "small inconsistency," Miller, Ulrich, and Rinkenauer (1999, p. 1465) noted that the failure to detect S-LRP and/ or R-LRP changes was possibly due to lower sensitivity of these time indexes than of RT to the experimental manipulation. Indeed, the shortening of RT due to intensity change was relatively small $(18 \mathrm{msec})$. Thus, it is quite possible that the effects on LRP onsets also were very small and remained undetected.

Nevertheless they concluded "that stimulus intensity need not affect the durations of simple motor processes in human information tasks" (p. 1468). In our view, this conclusion was not legitimate. In contrast to this claim, one may argue that the $18-\mathrm{msec}$ interval was equally distributed on sensory and motor processes and that this may be a reason why the effects remained undetected by the LRP method. Miller, Ulrich, and Rinkenauer (1999) apparently rejected this possibility on the basis of the effects on P300 and N100 waves of ERP. Indeed, they showed that P300 occurred sooner by $38 \mathrm{msec}$ and N100 by $26 \mathrm{msec}$ for loud than for soft tones. But by doing so, Miller, Ulrich, and Rinkenauer based their conclusion on those psychophysiological indexes that they had criticized in the introduction to their study. Moreover, the delay of P300 was more than twice as large as that of RT. This fits with their conclusion of two contradictory early processes, provided that one assumes that the $\mathrm{P} 300$ represents processes that proceed somewhere between those represented by N100 and S-LRP onset. But the reasons for the overall delay of P300 might simply be methodological: With intense stimuli and short responses, P300 might merge or overlap with the preceding P2 (as with the P250 complex with frequent stimuli in the oddball task; García-Larrea, Lukaszewicz, \& Mauguière, 1992), producing an underestimation of P300 latency. Therefore, when P300 is delayed with less intense stimuli and longer responses, the delay will be overestimated. Besides, P300 latency is not a pure measure of response-independent stimulus processing (Kotchoubey, 2002; Leuthold \& Sommer, 1998; Verleger, 1997), probably due to overlap of a stimulus- and a response-related subcomponent (Falkenstein, Hohnsbein, Hoormann, \& Blanke, 1990).

By the same token, one can also wonder whether Miller, Ulrich, and Rinkenauer's (1999) conclusion concerning no effect of brightness on R-LRP is justified, taking into account the relatively small overall change of RT they found with visual stimuli (ca. $28 \mathrm{msec}$ ). Indeed, one can argue that the small overall change of RT implies a correspondingly small effect of intensity on R-LRP. In such a case, the failure to find the effect on R-LRP might mean that it remained undetectable due to the insensitivity of the method.

\section{Present Study}

Summing up, we argue that the LRP approach suggested by Miller, Ulrich, and Rinkenauer (1999) may not yet have been suitably exploited to answer the question of whether motor processes are affected by stimulus intensity. The present study was designed to replicate Miller, Ulrich, and Rinkenauer's study with some variations for both visual (Experiment 1) and auditory (Experiments 2 and 3) stimuli.

First of all, Miller, Ulrich, and Rinkenauer used a "very simple two-alternative forced choice RT task ... to minimize the variability introduced by processes occurring before LRP onset" (p. 1461). If their account for the lack of intensity effect on LRP was correct, the task was still too difficult, leading to the van der Molen and Keuss effect. To avoid this complication, we used a simple, rather than a choice, task. With the simple task, lack of an intensity effect on LRP has to be assigned to the low sensitivity of LRP, rather than to mutual cancellation of the intensity influences on S-LRP. 
Second, we tried to find stimulation parameters that would make the experimental manipulation as effective as possible. In dark adaptation, simple RT to visual intensities is about $100 \mathrm{msec}$ longer for near-threshold intensities than for the highest intensities. The changes are smaller when the stimuli are presented on a bright background, as in Miller, Ulrich, and Rinkenauer's (1999) study (e.g., Bartlett \& MacLeod, 1954; Jaśkowski, 1985). Similar effects were reported for manipulations of loudness with auditory stimuli (Sanford, 1974). Thus, to obtain larger changes of RTs, we applied, in the case of visual stimuli, a larger range of intensities and dark adaptation. In the case of auditory stimuli, the range of loudness levels we could apply was more or less like that in Miller, Ulrich, and Rinkenauer's study. Nevertheless, the overall change of RT turned out to be three times as large as that in their study, probably because we used a simple, rather than a choice, response task. As was mentioned above, the intensity effect of loudness has been shown to be more complex for more demanding tasks since it may deteriorate accurate response selection, which is a major reason to focus on tasks in which responses are determined before target onset.

\section{EXPERIMENT 1}

\section{Method}

Participants. Eleven persons (6 males and 5 females; $18-24$ years of age, $M=20.8$ years, $S D=2.4$ ) recruited from the student population of Kazimierz Wielki University of Bydgoszcz took part in the experiment. All the participants were right-handed and had normal vision by self-report. The results from 2 participants were excluded. For 1 of the 2 participants, no LRP was visible in the averaged waveshape of the contraipsilateral difference wave (cf. Miller, Ulrich, \& Rinkenauer, 1999). The EEG data file of a 2nd participant was corrupted.

Stimuli and Apparatus. Visual stimuli were generated by means of a LED array. It consisted of $64(8 \times 8)$ red $(660 \mathrm{~nm})$ ultra-bright LEDs. The LEDs in the array were controlled by a microprocessor system that supplied every LED with a short current pulse. Luminance was changed by varying both the duration and the amplitude of the pulses. With this system, luminance could be varied in the range 1:104 identically for every LED. The refresh rate was $110 \mathrm{~Hz}$.

The stimuli were two patterns of LEDs arranged as "+" or " $X$ " signs $\left(1.9^{\circ} \times 1.9^{\circ}\right)$. Each stimulus was formed by five LEDs. Three luminance levels $\left(0.02,0.16\right.$, and $\left.79.6 \mathrm{~cd} / \mathrm{m}^{2}\right)$ were used. The stimuli lasted $250 \mathrm{msec}$. Two additional green LEDs $\left(0.16 \mathrm{~cd} / \mathrm{m}^{2}\right)$ located $1 \mathrm{~cm}$ left and right from the stimulus were provided to facilitate fixation. These two LEDs were on throughout the experiment.

No warning signal was used. Intertrial interval was sampled from an exponential distribution with a mean of $700 \mathrm{msec}$ plus a constant period of 2,700 msec. Trials were terminated by the participants' responses.

The participants were seated in an experimental chamber and viewed the LED matrix from a distance of approximately $70 \mathrm{~cm}$. Their right or left index fingers rested on the computer keyboard. They responded with the "left-ctrl" or "numpad enter" keys.

Task and Design. The participants were asked to make the same response to each stimulus irrespective of its shape. The total number of stimuli was 600 (200 replications $\times 3$ intensities). Stimulus intensities were arranged in random order. The session was divided into two blocks: In one block, the participants used their left hand, and in the other block, they used their right hand. The order of blocks was randomized.

EEG recordings and analysis. Electrophysiological responses were recorded by sintered $\mathrm{Ag}-\mathrm{AgCl}$ ring electrodes attached to an electrode cap (BrainCap). Responses were amplified by BrainAmp
(BrainProducts Inc.) amplifiers and were stored on disk with a sampling rate of $250 \mathrm{~Hz}$. EEG was recorded from $\mathrm{Cz}, \mathrm{C} 3, \mathrm{C} 4, \mathrm{Pz}, \mathrm{Oz}$, and both mastoids. The reference electrode was placed at Fz. For identifying ocular potentials in the EEG, the vertical electrooculogram (EOG) was measured with two electrodes above and beneath the left eye, and the horizontal EOG with two electrodes placed at the outer canthi of both eyes. The impedance was below $5 \mathrm{k} \Omega$ for all EEG and EOG recordings. Offline, trials were rereferenced to the average of both mastoids. Trials were excluded when there were zero lines, out-of-scale values, slow drifts larger than $50 \mu \mathrm{V}$, or fast shifts larger than $0.1 \mu \mathrm{V} / 50 \mathrm{msec}$. Transmission of ocular potentials was corrected from the EEG by linear regression. Furthermore, trials were excluded in which the participants did not press the key within a time window of 150-1,000 msec after stimulus onset.

Before averaging, each recording was adjusted by subtracting the baseline voltage from all time points. For both S-LRP and R-LRP averaging, the baseline corresponded to the mean voltage during the 100 -msec interval preceding the target stimuli.

The differences between the EEGs contralateral and ipsilateral to the response hand (LRPs) were determined for $\mathrm{C} 3$ and $\mathrm{C} 4$ in artifactfree, correctly responded trials separately for each intensity by calculating the average, over trials, of the $\mathrm{C} 3-\mathrm{C} 4$ difference in lefthand blocks and of the $\mathrm{C} 4-\mathrm{C} 3$ difference in right-hand blocks and then averaging these two averages to obtain the general contralateral minus ipsilateral difference. These individual averages were low-pass filtered (10-Hz upper bound) and also averaged across all participants (grand means) for display purposes, as well as for measuring LRP onset according to the jackknife procedure (jk50). The signals were time-locked either to the stimulus or to the response to compute the S-LRP and the R-LRP, respectively. The LRP onset latencies for each condition were derived by the jk50 method (cf. Mordkoff \& Gianaros, 2000) in which LRP onset was defined in the grand means as the point in time at which a criterion of $50 \%$ of the amplitude was reached, as recommended by Miller, Patterson, and Ulrich, 1998, and then was subjected to ANOVAs of the one-leave-out grand means (with each participant's LRP omitted from the averaging in one iteration of this procedure and employing a correction for the obtained $F$ value), as described by Ulrich and Miller (2001).

The ANOVA had one repeated measures factor, intensity, with three levels. Degrees of freedom were corrected by the GreenhouseGeisser coefficient.

\section{Results}

Reaction times. RTs shorter than $150 \mathrm{msec}$ and longer than $1,000 \mathrm{msec}$ were considered response errors and were discarded from further analysis (1.3\% of the trials). RTs decreased as an inverse function of luminance: 408 , 339 , and $300 \mathrm{msec}$ for $0.02,0.16,79.6 \mathrm{~cd} / \mathrm{m}^{2}$, respectively $\left[F(2,16)=140.2, M S_{\mathrm{e}}=322, p<.001\right]$. Therefore, the overall change of mean RT due to the intensity manipulation was 108 msec.

Stimulus-locked LRP. Mean S-LRPs for the three intensities averaged over all participants are depicted in Figure $1 \mathrm{~A}$. Their onset latencies were 226, 180, and $159 \mathrm{msec}$ for the three intensities. Thus, the overall acceleration of onset due to intensity manipulation was $67 \mathrm{msec}$. The effect of intensity was significant $\left[F(2,16)=26.0, M S_{\mathrm{e}}=\right.$ $627, p<.001]$

Response-locked LRP. Mean R-LRPs for the three intensities averaged over all participants are depicted in Figure 1B. The lines representing R-LRP for different intensities overlap considerably. Accordingly, the onsets of R-LRPs were not affected by intensities. The following means of R-LRP onset latencies were found: -120 , -122 , and $-119 \mathrm{msec}\left[F(2,15)=0.1, M S_{\mathrm{e}}=312\right.$, n.s. $]$. 


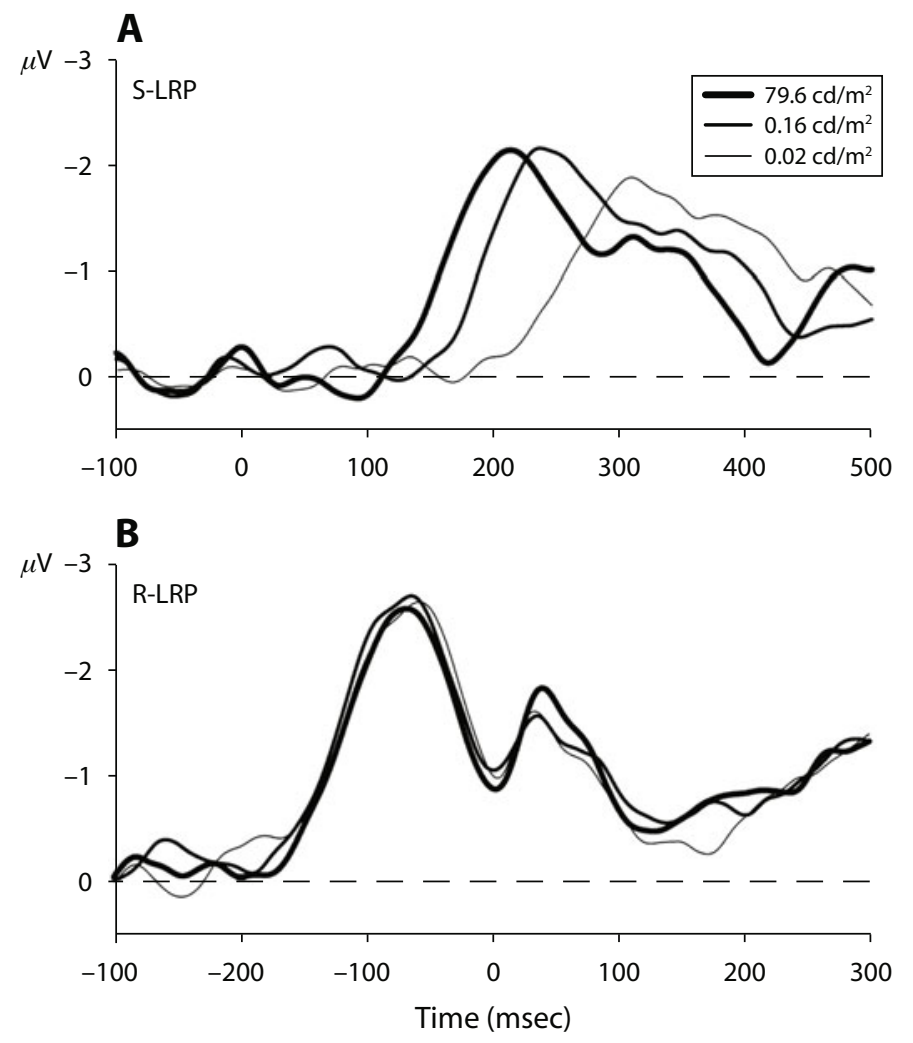

Figure 1. Lateralized readiness potentials (LRPs) obtained in Experiment 1 averaged over all participants: thick line, $0.02 \mathrm{~cd} / \mathrm{m}^{2}$; intermediate, $0.16 \mathrm{~cd} / \mathrm{m}^{2}$; thin line, $79.6 \mathrm{~cd} / \mathrm{m}^{2}$. (A) Stimulus-locked LRP (S-LRP). (B) Response-locked LRP (R-LRP).

\section{Discussion}

In accordance with Miller, Ulrich, and Rinkenauer's findings (1999), we found that visual intensity affected only the sensory part of RT. The lack of effect of intensity on the R-LRP suggests that processes depending on brightness are completed before the onset of LRP. Our experiment additionally showed that this is the case even when the intensity range is much larger and the task simpler than those in Miller, Ulrich, and Rinkenauer's experiment. In our second and third experiments, we focused on the locus of the effect of auditory stimulus intensity.

\section{EXPERIMENT 2}

\section{Method}

Participants. Eighteen persons recruited from the student population of Kazimierz Wielki University of Bydgoszcz took part in the experiment. The data from 3 persons were excluded because of equipment malfunction, and those from 2 additional persons because of absence of an LRP. The remaining participants were 4 males and 9 females $19-46$ years of age $(M=24.6$ years, $S D=7.4)$. All the participants were right-handed and had no hearing problems by self-report.

Apparatus and Procedure. The stimuli were sinusoidal 3000and $1000-\mathrm{Hz}$ tones of three different levels of sound pressure $(40,55$, and $70 \mathrm{dBA}$ ) lasting $300 \mathrm{msec}$, with rise and decay times of $10 \mathrm{msec}$. Each tone was delivered binaurally through padded earphones. The tones were generated by a Sound Blaster Audigy card. Generation of stimuli, timing, and registration of responses were under computer control. The participants responded to every stimulus independently of frequency and intensity with one hand in one block and with the other hand in the second block. The participants were asked to fixate their gaze on a cross drawn on the wall at a distance of ca. $70 \mathrm{~cm}$ from their head. The overall level of noise in the experimental chamber was about $60 \mathrm{dBA}$.

\section{Results}

Reaction times. RTs shorter than $110 \mathrm{msec}^{1}$ and longer than $1,000 \mathrm{msec}$ were considered response errors and were discarded from further analysis. About $1.2 \%$ of the trials were discarded due to this criterion. RTs decreased as a function of sound intensity level: 305, 271, and $251 \mathrm{msec}$ for 40,55 , and $70 \mathrm{dBA}$, respectively $[F(2,24)=$ $\left.90.1, M S_{\mathrm{e}}=105, p<.0001\right]$. Thus, the overall change of RT due to increasing intensity was $54 \mathrm{msec}$.

Stimulus-locked LRP. Mean S-LRPs for the three intensities, averaged over all participants, are depicted in Figure 2A. The ANOVA revealed a significant effect of intensity on S-LRP onset latency. S-LRP started 166, 117, and $100 \mathrm{msec}$ after sound onset $\left[F(2,24)=6.1, M S_{\mathrm{e}}=\right.$ $2,448, p=.007]$. Thus, $\mathrm{S}$-LRP onset latency changed due to stimulus intensity manipulation by about $66 \mathrm{msec}$.

Response-locked LRP. Mean R-LRPs for the three intensities averaged over all participants are depicted in Figure 2B. No effect of intensity is visible. The estimated mean latencies were $-108,-103$, and $-104 \mathrm{msec}$ $\left[F(2,24)=0.3, M S_{\mathrm{e}}=345\right.$, n.s. $]$. 


\section{Discussion}

Using a simple response task and, by and large, the same range of intensities as those in Miller, Ulrich, and Rinkenauer (1999), we obtained an effect of intensity on RT that was over three times larger than that in their study. This effect could be fully attributed to shortening of sensory, rather than motor, processes because S-LRP onset was shifted by more or less the same amount of time as $\mathrm{RT}^{2}$ and, simultaneously, no effect of intensity level on R-LRP onset was found.

\section{EXPERIMENT 3}

Usually, choice response tasks have been used in LRP studies. One of the reasons for this approach is that in simple response tasks, participants know in advance the hand with which they have to respond to the incoming stimuli, resulting in an advance preparation of the hand. This in turn might lead to a slow ramping potential preceding the LRP (Hackley \& Miller, 1995; Miller \& Low, 2001). Such a ramping potential renders the estimation of LRP onset more difficult. Indeed, some slight increase of negativity preceding the LRP may be seen in the results of Experiment 1 (up to 100 msec after stimulus onset), but not of Experiment 2. One may, however, argue that the ramping could be very slow and, therefore, would not be registered by an amplifier with a time constant of $10 \mathrm{sec}$.
Miller and Low argued that in spite of such a possible drift, LRP onset can be reliably estimated if the drift amplitude is independent of experimental conditions. Therefore, in Experiment 3, we used Miller and Low's task. Although they referred to it as a simple response task, in fact it differed markedly from what is usually called a simple response task and may be more appropriately denoted as a go/no-go task. First, an arrow presented before the test stimulus indicated the required response button that had to be pressed when the target occurred 1,250 msec after the cue ( $80 \%$ of the trials). Second, on some trials, no target was presented (i.e., catch trials; $20 \%$ of the trials), and responses had to be withheld.

\section{Method}

Participants. Twenty-four persons recruited from the local student population of the University of Finance and Management, Warsaw, took part in the experiment. The data from 4 persons were excluded because they showed no LRPs and those of 2 further persons because of unacceptable error levels (too many responses in the no-go trials and too many premature responses $[<110 \mathrm{msec}]$ in the go trials). The remaining participants, all right-handed, were 3 males and 15 females $19-29$ years of age $(M=21.1$ years, $S D=3.0)$. All reported having normal audition.

Apparatus and Procedure. The experiment was conducted in another laboratory. Therefore, the experimental conditions differed slightly from those applied in Experiment 2. First, the soundproofing was better, since the experimental chamber had walls, floor,

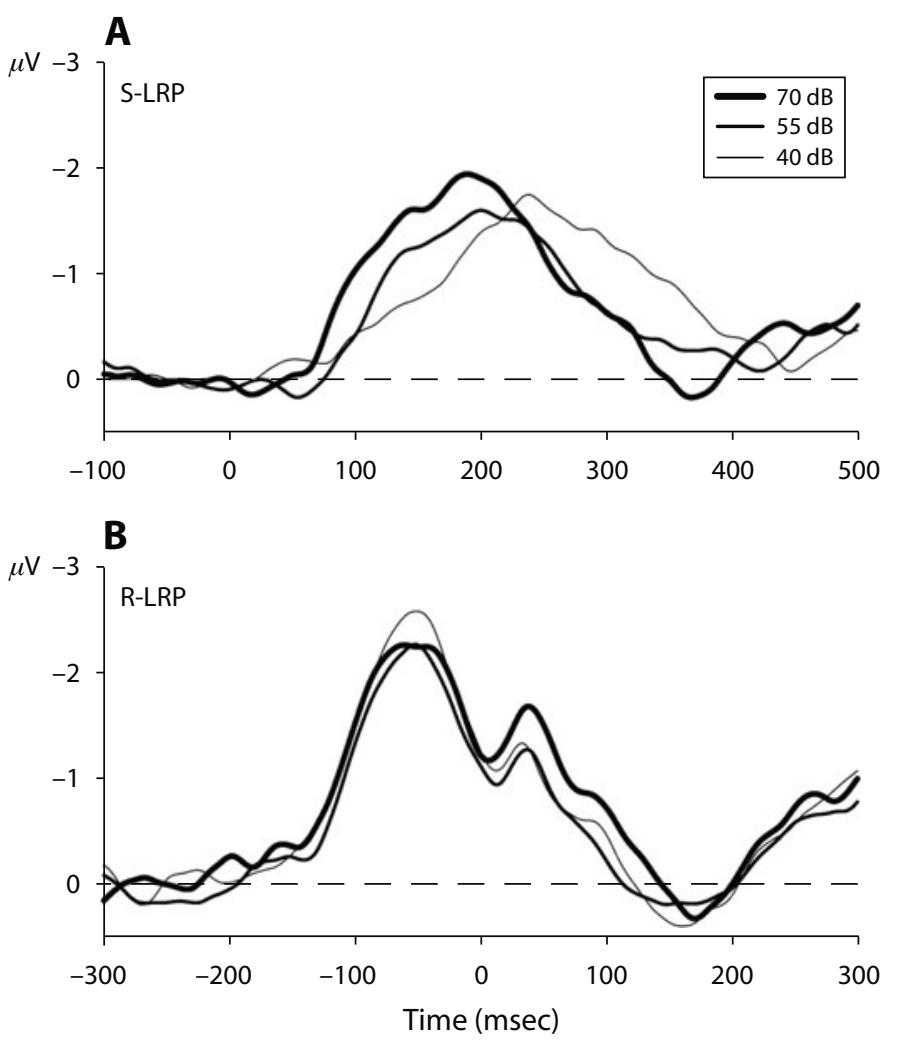

Figure 2. Lateralized readiness potentials (LRPs) obtained in Experiment 2 averaged over all participants: thick line, $70 \mathrm{~dB}$; intermediate, $55 \mathrm{~dB}$; thin line, $40 \mathrm{~dB}$. (A) Stimulus-locked LRP (S-LRP). (B) Responselocked LRP (R-LRP). 
and ceiling made of special sound-isolated materials. As a result, the overall noise level was lower than $20 \mathrm{dBA}$. Second, EEG was recorded by DC amplifiers (QuickAmp, BrainProducts Inc.) with common average reference.

The stimuli were tones of constant frequency $(1000 \mathrm{~Hz})$ and of only two intensity levels ( 34 and $89 \mathrm{~dB}$ ). The level of the higher intensity was increased (to $89 \mathrm{~dB}$ ) to optimize the chances for finding some arousal-dependent shortening of the motor part of RT (see the General Discussion section).

Each trial started with presentation of an arrow pointing left or right. The arrow was presented in the center of the monitor screen and lasted $250 \mathrm{msec}$. The sound was presented with a probability of $80 \% 450 \mathrm{msec}$ after arrow offset. The participants were instructed to respond with the hand indicated by the arrow cue if a sound was presented (go trials) but to refrain from responding if no sound was presented (no-go trials). Two hundred sixty go trials (130 for each intensity) and 65 no-go trials were presented during one experimental session. The baseline for the S-LRP and the R-LRP was set from -100 to $0 \mathrm{msec}$ before target onset.

All other details were the same as those in Experiment 2.

\section{Results and Discussion}

Reaction times. Mean percentage of responses in catch trials was $4.1 \%$. In the following, only go trials were analyzed. RTs shorter than $110 \mathrm{msec}$ and longer than $1,000 \mathrm{msec}$ were considered response errors and were discarded from further analysis. About $2.4 \%$ of the trials were discarded due to this criterion.
As in the previous experiments, the participants responded more quickly to stimuli of high intensity (301 $\mathrm{msec})$ than to those of low intensity $(338 \mathrm{msec})$ $\left[F(1,17)=68.9, M S_{\mathrm{e}}=194, p<.001\right]$; therefore, the overall intensity effect was equal to $37 \mathrm{msec}$. This overall change of RTs turned out to be significantly smaller than that obtained in Experiment $2\left[F(1,29)=175.9, M S_{\mathrm{e}}=\right.$ $182, p<.001]$, even though the intensity range was larger. A possible reason for this difference is the better soundproofing, which rendered the soft tones more hearable.

LRP onset latency. S-LRPs and R-LRPs for soft and loud tones are depicted in Figure 3. In agreement with the results of Experiment 2, S-LRP onset was delayed for soft tones in respect to loud tones by about $40 \mathrm{msec}$ [ $88 \mathrm{vs}$. $\left.128 \mathrm{msec} ; F(1,17)=29.9, M S_{\mathrm{e}}=460, p<.001\right]$. Stimulus intensity did not affect R-LRP onset. R-LRP onsets were -109 and $-109 \mathrm{msec}$ for soft and loud tones, respectively $\left[F(1,17)=0.0, M S_{\mathrm{e}}=588\right.$, n.s. $]$. These results corroborate those obtained in Experiment 2.

\section{GENERAL DISCUSSION}

\section{Intensity Affects Only Early Processing}

The main goal of this study was to answer the question of which stage of sensory processing is affected by stimulus intensity in a simple reaction task. The locus of

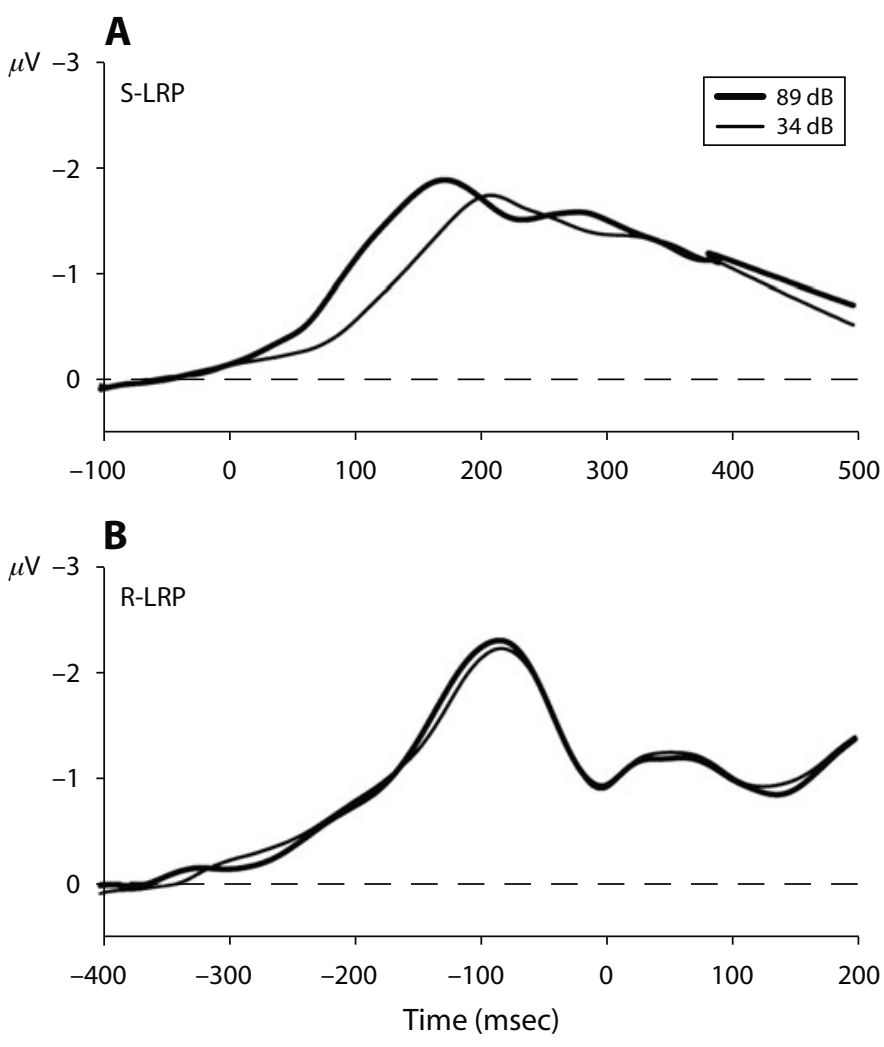

Figure 3. Lateralized readiness potentials (LRPs) obtained in Experiment 3 averaged over all participants: thick line, $89 \mathrm{~dB}$; intermediate, 34 dB. (A) Stimulus-locked LRP (S-LRP). (B) Response-locked LRP (R-LRP). 
this effect has been the focus of a series of studies over the last 50 years. Miller, Ulrich, and Rinkenauer (1999) have recently questioned these attempts on the grounds of methodological and conceptual weaknesses and have proposed using LRP as a chronopsychophysiological index, which they suggested to be free from these weaknesses. LRP onset provides the possibility of assessing the influence of a factor on early sensory processing, which ends before LRP onset, and on late motor processing, which starts with LRP onset and ends with the participant's overt response. Their results provided clear evidence for a sensory locus of the intensity effect in the case of visual stimuli. Unfortunately, their results with auditory stimuli were not as clear: The effect of loudness was found neither for S-LRP nor for R-LRP, although RTs for high-intensity stimuli were $18 \mathrm{msec}$ shorter, on average, than those for low-intensity stimuli. Two possible reasons might be responsible for this failure. First, being affected by the background noise of the EEG and, therefore, not as sensitive to experimental manipulation as RT, LRP onset might not be significantly affected by intensity. Second, since Miller, Ulrich, and Rinkenauer used a choice task, shortening of perceptual processes due to increase of loudness could be canceled by an elongation of arousal-dependent response selection.

In the present study, we examined simple, rather than choice, reactions and a larger range of intensities. It is probably due to both factors that RTs were much more effectively affected (100 msec in the case of visual stimuli and $40-60 \mathrm{msec}$ in the case of auditory stimuli) than in Miller, Ulrich, and Rinkenauer's (1999) study. In accordance with Miller, Ulrich, and Rinkenauer's findings, visual intensity affected only the sensory part of RT - that is, the latency of stimulus-LRP onset - and not the LRPresponse interval. Correspondingly, but unlike Miller, Ulrich, and Rinkenauer, RT changes due to increasing loudness were reflected in shifts of S-LRP onsets, and not of R-LRP onsets.

In conclusion, we provided that data converged with earlier evidence in showing that only the sensory part of RT is affected by stimulus intensity.

\section{Limitations}

Two facts may limit our conclusion. First, the highest intensity used in our and Miller, Ulrich, and Rinkenauer's (1999) auditory experiments was around 70-90 dB. Conversely, it is known that loud auditory stimuli can evoke arousal, which is assumed to shorten some stages of RT. Although it is not completely clear on which stages arousal exerts its effect, there is some indirect evidence that motor processes are also affected. For instance, participants respond more forcefully to loud than to soft sounds (Jaśkowski, Rybarczyk, Jaroszyk, \& Lemański, 1995; Miller, Franz, \& Ulrich, 1999). This effect is usually assigned to arousal. Bearing this in mind, one can wonder if arousal-mediated shortening of motor processes might occur and would be reflected in R-LRP with stimuli louder than the $70-$ to $90-\mathrm{dB}$ tones. By the same token, one can suspect that arousal would have accelerated motor processes if the visual stimuli had been still brighter or larger than the present bright visual stimuli (Niemi \& Lehtonen, 1982; Sanders, 1975). This doubt is weakened by Hackley and Valle-Inclán $(1998,1999)$, who showed that the accelerating effect of accessory auditory stimulation, which is also attributed to arousal, affected only S-LRP onset.

Second, as was mentioned in the introduction, task complexity seems to modulate the RT-intensity relation, at least for auditory stimuli. Van der Molen and Keuss (Keuss \& van der Molen, 1982; van der Molen \& Keuss, 1979,1981 ) showed that RTs to very loud auditory stimuli were longer than those to stimuli of moderate intensity. This effect was recently demonstrated by Jaśkowski and Włodarczyk (2006) for large and bright visual stimuli. The question of the locus of this paradoxical prolongation of RT remains open. Some evidence derived from an AFM experiment indicates that this effect is due to prolongation of sensory, rather than motor, processes (van der Molen $\&$ Keuss, 1979). However, further research is needed to settle this issue.

\section{AUTHOR NOTE}

This study was supported by Grant 1H01F 10127 from the Polish Ministry of Science and Higher Education. Correspondence concerning this article should be addressed to P. Jaśkowski, Department of Cognitive Psychology, University of Finance and Management, Pawia 55, 01-030 Warsaw, Poland (e-mail: jaskowski@vizja.pl).

\section{REFERENCES}

BAnd, G. P., \& Miller, J. (1997). Mental rotation interferes with response preparation. Journal of Experimental Psychology: Human Perception \& Performance, 23, 319-338.

Bartlett, N. R., \& MacLeod, S. (1954). Effect of flash and field luminance upon human reaction time. Journal of Optical Society of America, 44, 306-311.

Brauner, J. D., \& Lit, A. (1976). The Pulfrich effect, simple reaction time, and time intensity discrimination. American Journal of Psychology, 89, 105-114.

Callaway, E., Halliday, R., Naylor, H., \& Thouvenin, D. (1984). The latency of the average is not the average of the latencies. Psychophysiology, 21, 571 .

Coles, M. G. H. (1989). Modern mind-brain reading: Psychophysiology, physiology, and cognition. Psychophysiology, 26, 251-269.

EIMER, M., \& Coles, M. G. H. (2003). The lateralized readiness potential. In M. Jahanshahi \& M. Hallett (Eds.), The Bereitschaftspotential: Movement-related cortical potentials (pp. 229-248). New York: Kluwer.

Everett, B. L., Hochhaus, L., \& Brown, J. R. (1985). Letter-naming as a function of intensity, degradation, S-R compatibility, and practice. Perception \& Psychophysics, 37, 467-470.

Falkenstein, M., Hohnsbein, J., Hoormann, J., \& Blanke, L. (1990). Effects of errors in choice reaction tasks on the ERP under focused and divided attention. In C. H. M. Brunia, A. W. K. Gaillard, \& A. Kok (Eds.), Psychophysiological brain research (pp. 192-195). Tilburg: Tilburg University Press.

García-Larrea, L., Lukaszewicz, A.-C., \& Mauguière, F. (1992). Revisiting the oddball paradigm: Non-target vs neutral stimuli and the evaluation of ERP attentional effects. Neuropsychologia, 30, 723741.

HACKLEY, S. A., \& Miller, J. O. (1995). Response complexity and precue interval effects on the lateralized readiness potential. Psychophysiology, 32, 230-241.

Hackley, S. A., \& Valle-Inclán, F. (1998). Automatic alerting does not speed late motoric processes in a reaction-time task. Nature, 391, 786-788.

HaCKLEY, S. A., \& VALLE-INCLÁN, F. (1999). Accessory stimulus effects on response selection: Does arousal speed decision making? Journal of Cognitive Neuroscience, 11, 321-329. 
JAŚKOWSKI, P. (1985). The effect of visual adaptation on simple motor reaction time: Pt. I. Studia Psychologica, 27, 191-201.

JAŚKOWSKI, P. (1992). Temporal-order judgment and reaction time for short and long stimuli. Psychological Research, 54, 141-145.

JAŚKOWSKI, P. (1996). Simple reaction time and perception of temporal order: Dissociations and hypotheses. Perceptual \& Motor Skills, 82, 707-730.

JAŚKowsKi, P., Pruszewicz, A., \& ŚwidzińSKI, P. (1990). VEP latency and some properties of simple motor reaction-time distribution. Psychological Research, 52, 28-34.

JAŚKOWSKI, P., RYBARCZYK, K., \& JAROSZYK, F. (1994). The relationship between latency of auditory evoked potentials, simple reaction time and stimulus intensity. Psychological Research, 56, 59-65.

JAŚKoWski, P., RYBARCZYK, K., JAROSZYK, F., \& LEMAŃSKi, D. (1995). The effect of stimulus intensity on force output in simple reaction time task in humans. Acta Neurobiologiae Experimentalis, 55, 57-64.

JAŚKOWSKI, P., \& VerLeger, R. (2000). Attentional bias toward lowintensity stimuli: An explanation for the intensity dissociation between reaction time and temporal order judgment? Consciousness \& Cognition, 9, 435-456.

JAŚKOWSKI, P., \& WŁODARCZYK, D. (2006). Task modulation of the effect of brightness on reaction time and response force. International Journal of Psychophysiology, 61, 98-112.

Kammer, T., Lehr, L., \& Kirschfeld, K. (1999). Cortical visual processing is temporally dispersed by luminance in human subjects. Neuroscience Letters, 263, 133-136.

Keuss, P. J. G., \& Van der Molen, M. W. (1982). Positive and negative effects of stimulus intensity in auditory reaction tasks: Further studies on immediate arousal. Acta Psychologica, 52, 61-72.

Kotchoubey, B. (2002). Do event-related brain potentials reflect mental (cognitive) operations? Journal of Psychophysiology, 16, 129-149.

KüLPE, O. (1895). Outlines of psychology (E. B. Titchener, Trans.). New York: Macmillan.

LeUtHOLD, H. (2003). Programming of expected and unexpected movements: Effects on the onset of the lateralized readiness potential. Acta Psychologica, 114, 83-100.

Leuthold, H., \& Sommer, W. (1998). Postperceptual effects and P300 latency. Psychophysiology, 35, 34-46.

Leuthold, H., Sommer, W., \& Ulrich, R. (1996). Partial advance information and response preparation: Inferences from the lateralized readiness potential. Journal of Experimental Psychology: General, 125, 307-323.

Meyer, D. E., Osman, A., Irwin, D. E., \& Yantis, S. (1988). Modern mental chronometry. Biological Psychology, 26, 3-67.

Miller, J. [O.], Franz, V., \& Ulrich, R. (1999). Effects of auditory stimulus intensity on response force in simple, go/no-go, and choice RT tasks. Perception \& Psychophysics, 61, 107-119.

Miller, J. O., \& Low, K. (2001). Motor processes in simple, go/no-go, and choice reaction time tasks: A psychophysiological analysis. Journal of Experimental Psychology: Human Perception \& Performance, 27, 266-289.

Miller, J. O., \& PaChella, R. G. (1973). Locus of stimulus probability effect. Journal of Experimental Psychology, 101, 227-231.

Miller, J. O., \& PaChella, R. G. (1976). Encoding processes in memory scanning tasks. Memory \& Cognition, 4, 501-506.

Miller, J. [O.], Patterson, T., \& Ulrich, R. (1998). Jackknifebased method for measuring LRP onset latency differences. Psychophysiology, 35, 99-115.

Miller, J. [O.], \& UlRich, R. (1998). Locus of the effect of the number of alternative responses: Evidence from the lateralized readiness potential. Journal of Experimental Psychology: Human Perception \& Performance, 24, 1215-1231.

Miller, J. [O.], Ulrich, R., \& Rinkenauer, G. (1999). Effects of stimulus intensity on the lateralized readiness potential. Journal of Experimental Psychology: Human Perception \& Performance, 25, 1454-1471.

Mordkoff, J. T., \& Gianaros, P. J. (2000). Detecting the onset of the lateralized readiness potential: A comparison of available methods and procedures. Psychophysiology, 37, 347-360.

Morgan, M. J. (1976). Pulfrich effect and the filling in of apparent motion. Perception, 5, 187-195.

Morgan, M. J. (1977). Differential visual persistence between the two eyes: A model for the Fertsch-Pulfrich effect. Journal of Experimental Psychology: Human Perception \& Performance, 3, 484-495.

Morgan, M. J., \& Thompson, P. (1975). Apparent motion and the Pulfrich effect. Perception, 4, 3-18.

Müller-Gethmann, H., Ulrich, R., \& Rinkenauer, G. (2003). Locus of the effect of temporal preparation: Evidence from the lateralized readiness potential. Psychophysiology, 40, 597-611.

NIEMI, P. (1979). Stimulus intensity effects on auditory and visual reaction processes. Acta Psychologica, 43, 299-312.

Niemi, P., \& Lehtonen, E. (1982). Foreperiod and visual stimulus intensity: A reappraisal. Acta Psychologica, 50, 73-82.

Osman, A., Lou, L., Müller-Gethmann, H., Rinkenauer, G., MatTes, S., \& UlRich, R. (2000). Mechanisms of speed-accuracy tradeoff: Evidence from covert motor processes. Biological Psychology, 51, 173-199.

Osman, A., \& Moore, C. M. (1993). The locus of dual-task interference: Psychological refractory effects on movement-related brain potentials. Journal of Experimental Psychology: Human Perception \& Performance, 19, 1292-1312.

Pachella, R. G. (1974). The interpretation of reaction time in information processing research. In B. Kantowitz (Ed.), Human information: Tutorials in performance and cognition (pp. 573-594). Hillsdale, NJ: Erlbaum.

Pachella, R. G., \& Miller, J. O. (1976). Stimulus probability and samedifferent classification. Perception \& Psychophysics, 19, 29-34.

RaAb, D., Fehrer, E., \& Hershenson, M. (1961). Visual reaction time and the Broca-Sulzer phenomenon. Journal of Experimental Psychology, 61, 193-199.

Rinkenauer, G., Osman, A., Ulrich, R., Müller-Gethmann, H., \& MAtTES, S. (2004). On the locus of speed-accuracy trade-off in reaction time: Inferences from the lateralized readiness potential. Journal of Experimental Psychology: General, 133, 261-282.

Roufs, J. A. J. (1974). Dynamic properties of vision: V. Perception lag and reaction time in relation to flicker and flash thresholds. Vision Research, 14, 853-869.

SANDERs, A. F. (1975). The foreperiod effect revisited. Quarterly Journal of Experimental Psychology, 27, 591-598.

Sanders, A. F., \& ANDRIESSEN, J. E. B. (1978). A suppressing effect of response selection on immediate arousal in a choice reaction time. Acta Psychologica, 42, 181-186.

SANFORD, A. J. (1971). Effect of changes in the intensity of white noise on simultaneity judgments and simple reaction time. Quarterly Journal of Experimental Psychology, 23, 296-303.

SANFORD, A. J. (1974). Attention bias and the relation of perception lag to simple reaction time. Journal of Experimental Psychology, 102, 443-446.

SCHWeicKert, R., DAHN, C., \& McGuigan, K. (1988). Intensity and number of alternatives in hue identification: Piéron's law and choice reaction time. Perception \& Psychophysics, 44, 383-389.

Shwartz, S. P., Pomerantz, J. R., \& Egeth, H. E. (1977). State and process limitations in information processing: An additive factors analysis. Journal of Experimental Psychology: Human Perception \& Performance, 3, 403-410.

Smulders, F. T. Y., Kenemans, J. L., \& KoK, A. (1994). A comparison of different methods for estimating single-trial P300 latencies. Electroencephalography \& Clinical Neurophysiology, 92, 107-114.

Smulders, F. T. Y., KoK, A., Kenemans, J. L., \& Bashore, T. R. (1995). The temporal selectivity of additive factor effects on the reaction process revealed in ERP component latencies. Acta Psychologica, 90, 97-109.

Stanovich, K. E., \& Pachella, R. G. (1977). Encoding, stimulusresponse compatibility, and stages of processing. Journal of Experimental Psychology: Human Perception \& Performance, 3, 411-421.

SternberG, S., \& KNOLL, R. L. (1973). The perception of temporal order: Fundamental issues and a general model. In S. Kornblum (Ed.), Attention and performance IV (pp. 629-685). New York: Academic Press.

Thomas, R. D. (2006). Processing time predictions of current models of perception in the classic additive factors paradigm. Journal of Mathematical Psychology, 50, 441-455.

Ulrich, R., Mattes, S., \& Miller, J. [O.] (1999). Donders' assumption of pure insertion: An evaluation on the basis of response dynamics. Acta Psychologica, 102, 43-75.

UlRich, R., \& MilleR, J. [O.] (2001). Using the jackknife-based scor- 
ing method for measuring LRP onset effects in factorial designs. Psychophysiology, 38, 816-827.

van der Lubbe, R. H. J., Havik, M. M., BekKer, E. M., \& Postma, A. (2006). Task-dependent exogenous cuing effects depend on cue modality. Psychophysiology, 43, 145-160.

van der Lubbe, R. H. J., Jaś́xowski, P., WauschKuhn, B., \& VerLEGER, R. (2001). Influence of time pressure in a simple response task, a choice-by-location task, and the Simon task. Journal of Psychophysiology, 15, 241-255.

van der Molen, M. W., \& Keuss, P. J. G. (1979). The relationship between reaction time and intensity in discrete auditory tasks. Quarterly Journal of Experimental Psychology, 31, 95-102.

van Der Molen, M. W., \& Keuss, P. J. G. (1981). Response selection and the processing of auditory intensity. Quarterly Journal of Experimental Psychology, 33, 177-184.

van der Molen, M. W., \& Orlebeke, J. F. (1980). Phasic heart rate change and the U-shaped relationship between choice reaction time and auditory signal intensity. Psychophysiology, 17, 471-481.

Vaughan, H. G., JR., Costa, L. D., \& Gilden, L. (1966). The functional relation of visual evoked response and reaction time to stimulus intensity. Vision Research, 6, 645-656.
VERLEGER, R. (1997). On the utility of P3 latency as an index of mental chronometry. Psychophysiology, 34, 131-156.

Williams, J. M., \& Lit, A. (1983). Luminance-dependent visual latency for the Hess effect, Pulfrich effect, and simple reaction time. Vision Research, 23, 171-179.

WiLSON, A. J., \& LIT, A. (1981). Effects of photopic annulus luminance level on reaction time and on the latency of evoked cortical potential responses to target flashes. Journal of the Optical Society of America, 71, 1481-1486.

\section{NOTES}

1. We used 110 msec as a lower RT limit because RTs to auditory stimuli are known to be shorter than those to visual stimuli.

2. The argument of Meyer et al. (1988) also applies here, as onset latencies are compared with RTs. So this argument should be taken with caution.

(Manuscript received January 10, 2007; revision accepted for publication May 14, 2007.) 